\section{Conquering Methicillin Resistant Staphylococcus aureus: Perspectives and Treatment Options}

\section{Abstract}

Exploring optimal cure of Methicillin Resistant Staphylococcus aureus (MRSA), has been consistently challenged by clinical physicians and microbiologist. The fatal bacterial infection, Methicillin Resistant Staphylococcus aureus (MRSA), shows unique resistance; when selected drugs are tested on human patients. If holistic approach is overlooked, less possibilities are left for medication to curtail this lethal toxicity. If single range of drug treatment is exercised only, the associated complications and consequences of infections may proliferate beyond threshold levels. The research article is an outcome from primary microbial data collection (from urine and blood) in hospital. The focus of experiment is to scrutinize the highest risk vulnerable hospital area including sampled fluid. The preventive and therapeutic measures are discussed along with multiple substitutes of medication with prudent selection to achieve targeted and optimum outcome.

\section{Keywords}

Staphylococcus aureus, ATCC 25923, MRSA, Pakistan, Options in Drug Therapy

\section{Introduction}

Microbiologists are witnessing an exponential growth in infectious human diseases through Staphylococcus aureus (S. aureus), which is exactly known as Methicillin Sensitive Staphylococcus aureus (MSSA) [1]. In this case, bacterial skin infections are due to the strains (i.e. invasive) of Methicillin Resistant Staphylococcus aureus (MRSA) [2]. The microbe has latency to severely resist antibiotics as observed in the last decade. The human race is facing significant morbidity caused by these lethal infections. These are also cause of constant worry (including both economic and financial) on health care system. The focus of this
Anas Rashid1,* Hamza Rashid 2,3, Usamah Rashid Qureshi4,5, Aiman Rashid ${ }^{6}$

1 Hamdard Institute of Pharmaceutical Sciences (HIPS), Hamdard University Islamabad Campus (HUIC), Islamabad, Pakistan.

2 Department of Computer Sciences, Faculty of Natural Sciences, Quaid-i-Azam University (QAU), Islamabad, Pakistan.

3 Faculty of Computer Science, Preston University Islamabad Campus, Islamabad, Pakistan.

4 Department of Business Studies, Faculty of Economics and Business Studies, Pakistan Institute of Development Economics (PIDE), Quaid-i-Azam University Campus, Islamabad, Pakistan.

5 Department of Electrical Engineering, Faculty of Engineering Sciences, Army Public College of Management and Sciences (APCOMS), Rawalpindi, Pakistan.

6 Department of Design and Manufacturing Engineering, School of Mechanical and Manufacturing Engineering (SMME), National University of Sciences and Technology (NUST), NUST Campus, Islamabad, Pakistan.

\section{Contact information:}

Mr. Anas Rashid, (FTJ, Pharm-D).

Tel: (92) (331)5036088

Address: Hamdard Institute of Pharmaceutical Sciences (HIPS), Hamdard University Islamabad Campus (HUIC), Islamabad, Pakistan.

झ anas.rashid_94@hotmail.com 
empirical study is to propose an ingenious approach to find out optimal solution by applying preventive measures to control epidemic. It also focuses on using localized treatment and alternative medicines to cure and treat the menace of infections produced by MRSA in human [3].

\section{Perspectives and Approaches}

People not involved in health care settings are often less aware of this silent and lethal epidemic. This lack of awareness lies in significance of risk, perils of hospital acquired MRSA infection, and potential threat to overall health care system. A significant public behavioural change is needed in order to control this global menace as well as a well-informed public.

Controlling MRSA is a clinical challenge faced by clinicians across the world [4]. The objective of the study is to figure out optimal and convenient methods to treat infections caused by MRSA in human. The focus of research is to consider alternative medicine including natural, herbal, ayurvedic, homeopathic, and Chinese medicine. Modern therapeutic methods like radio waves, laser therapy, and nuclear and radioactive radiations are essential as well as effective. These not only boost natural physiological immune system but also efficiently reduce the infectious effects and therapeutic side effects on human body [5].

\section{Location}

S. aureus is found abundantly in damp healthcare environment. People who are weaker, older and sicker have weaker immune system and may get infected easily. Many individuals either living or functioning closely together provide congenial setting for transmission of infectious diseases. It is also reported that people may carry this infection without having any visible indications.

It is a highly contagious bacterial species found throughout the ecosystem $[5,6]$. The microorganism invades the skin and enters deeper tissues. As in septicaemia, it multiplies to cause a localized or systemic response. The patient gets infected with the growth of its population.

\section{Origination}

The choice of antibiotics as efficient and effective treatment is reduced after the maturity of infection. Such methods are expensive and possibly show harmful side effects to the patient. Recent evidence supports that domestic pets like cat, dog and hen can transmit MRSA to their owners [7]. Production of $\beta$ - lactamase enzyme in the affected area is the main cause of microbial resistance. Some strain of MRSA are labelled as epidemic strains (EMRSA) [8]. Seventeen variants of EMRSA strain have been explored in the globe [9]. Recently, common strain variant to affect hospitals is EMRSA sixteen $[10,11]$.

\section{Material and Methods}

Holy Family Hospital is an eight hundred bed tertiary teaching hospital located in the city Rawalpindi, Pakistan. An empirical study on MRSA was conducted here from November to December 2014. The patients were clinically spotted. Later on, the data was gathered using the information and support system from the targeted hospital. For this purpose, collection of samples was gathered in containers which were pre-sterile using aseptic technique by healthcare team and transported to the laboratory by brain - heart infusion broth (BHIB) medium in controlled environment without delay for immediate processing.

Mannitol Salt agar and Chocolate agar were used for the identification and isolation of $S$. aureus [12]. The collected samples were inoculated onto Chocolate agar as well as on Mannitol Salt agar [13]. Two tests were used to identify the type of bacteria namely; coagulase and catalase [14]. The identification of $S$. aureus suspicious grown colonies was based on gram staining and standard biochemical reactions, including catalase and coagulase [15]. 
The Chocolate agar plates were incubated in a ten percent $(10 \%)$ carbon dioxide incubator at $370 \mathrm{C}$ for 24 hours. The Mannitol Salt agar (MSA) plates were incubated for 18-72 hours at 30-35oC [16]. Standard microbiological techniques are applied to identify particular bacterial characteristics [17].

Methicillin Resistant Staphylococcus aureus was identified by using Vancomycin $(30 \mu \mathrm{g})$ and Oxacillin $(1 \mu \mathrm{g})$ disks as recommended by Clinical and Laboratory Standard Institute (CLSI) [18]. Inducible resistance was identified in $S$. aureus by disk approximation test [19]. The data was documented and analysed for the completion of this study. A reference strain S. aureus ATCC 25923 was used for the standardization of antibiotic susceptibility testing $[20,21]$.

\section{Results}

A total of 920 samples were processed from in-patients; which comprises 503 samples of Blood and remaining were Urine (Table 1). The sample contained 37\% MRSA-identified in ICU and Special Care Baby Unit (both Blood and Urine processed samples) which depicted as clinically high risk. Whereas Vascular Unit contains 30\% MRSA Positive samples (both Blood and Urine processed samples) which depicted as moderate risk. General Medicine Unit contains 25\% MRSA Positive samples (both Blood and Urine processed samples) which depicted as low risk. Psychogeriatric Unit contains 15\% MRSA identified samples (both Blood and Urine processed samples) which depicted as clinically minimal risk. Sampled data tabulated in Table 1 is graphically depicted in Figure 1 and Figure 2. To conclude, overall the study showed high prevalence of MRSA (32\%)

Table 1. Fluid Samples Processed from Hospitalized In-Patients.

\begin{tabular}{|c|c|c|c|c|c|c|}
\hline \multirow{2}{*}{$\begin{array}{l}\text { Risk in } \\
\text { Percentage }\end{array}$} & \multirow[b]{2}{*}{ Unit or Department } & \multicolumn{2}{|c|}{ Blood (Samples Processed) } & \multicolumn{2}{|c|}{ Urine (Samples Processed) } & \multirow{2}{*}{$\begin{array}{c}\text { Total Samples } \\
\text { with MRSA } \\
\text { Positive }\end{array}$} \\
\hline & & $\begin{array}{l}\text { Collected } \\
\text { Samples }\end{array}$ & $\begin{array}{l}\text { Samples with } \\
\text { MRSA Positive }\end{array}$ & $\begin{array}{l}\text { Collected } \\
\text { Samples }\end{array}$ & $\begin{array}{l}\text { Samples with } \\
\text { MRSA Positive }\end{array}$ & \\
\hline \multirow{8}{*}{$\begin{array}{l}\text { High } \\
(\geq 31 \%)\end{array}$} & Special Care Baby Unit & 37 & 14 & 28 & 10 & $37 \%$ \\
\hline & Intensive Care Unit & 172 & 68 & 137 & 46 & $37 \%$ \\
\hline & Burns Unit & 22 & 8 & 20 & 7 & $36 \%$ \\
\hline & Transplant Unit & 10 & 3 & 10 & 4 & $35 \%$ \\
\hline & Cardiothoracic & 17 & 9 & 25 & 5 & $33 \%$ \\
\hline & Orthopedic & 14 & 7 & 13 & 2 & $33 \%$ \\
\hline & General Surgery & 35 & 11 & 24 & 8 & $32 \%$ \\
\hline & Urology & 40 & 9 & 45 & 17 & $31 \%$ \\
\hline \multirow{6}{*}{$\begin{array}{l}\text { Moderate } \\
(\geq 26 \%)\end{array}$} & Vascular & 18 & 7 & 15 & 3 & $30 \%$ \\
\hline & Neonatal & 9 & 3 & 8 & 2 & $29 \%$ \\
\hline & Obstetrics & 8 & 2 & 9 & 3 & $29 \%$ \\
\hline & Trauma & 17 & 5 & 8 & 2 & $28 \%$ \\
\hline & Gynecology & 10 & 3 & 8 & 2 & $28 \%$ \\
\hline & Dermatology & 34 & 8 & 25 & 8 & $27 \%$ \\
\hline \multirow{2}{*}{$\begin{array}{l}\text { Low } \\
(\geq 21 \%)\end{array}$} & General Medicine & 7 & 2 & 5 & 1 & $25 \%$ \\
\hline & Children (not neonates) & 16 & 3 & 6 & 2 & $23 \%$ \\
\hline \multirow{3}{*}{$\begin{array}{l}\text { Minimal } \\
(<21 \%)\end{array}$} & Psychiatric & 18 & 5 & 10 & 0 & $18 \%$ \\
\hline & Psychogeriatric & 19 & 3 & 21 & 3 & $15 \%$ \\
\hline & Grand Total & 503 & 170 & 417 & 125 & $32 \%$ \\
\hline
\end{tabular}


Figure 1: Processed Samples of Urine.

\section{Urine}

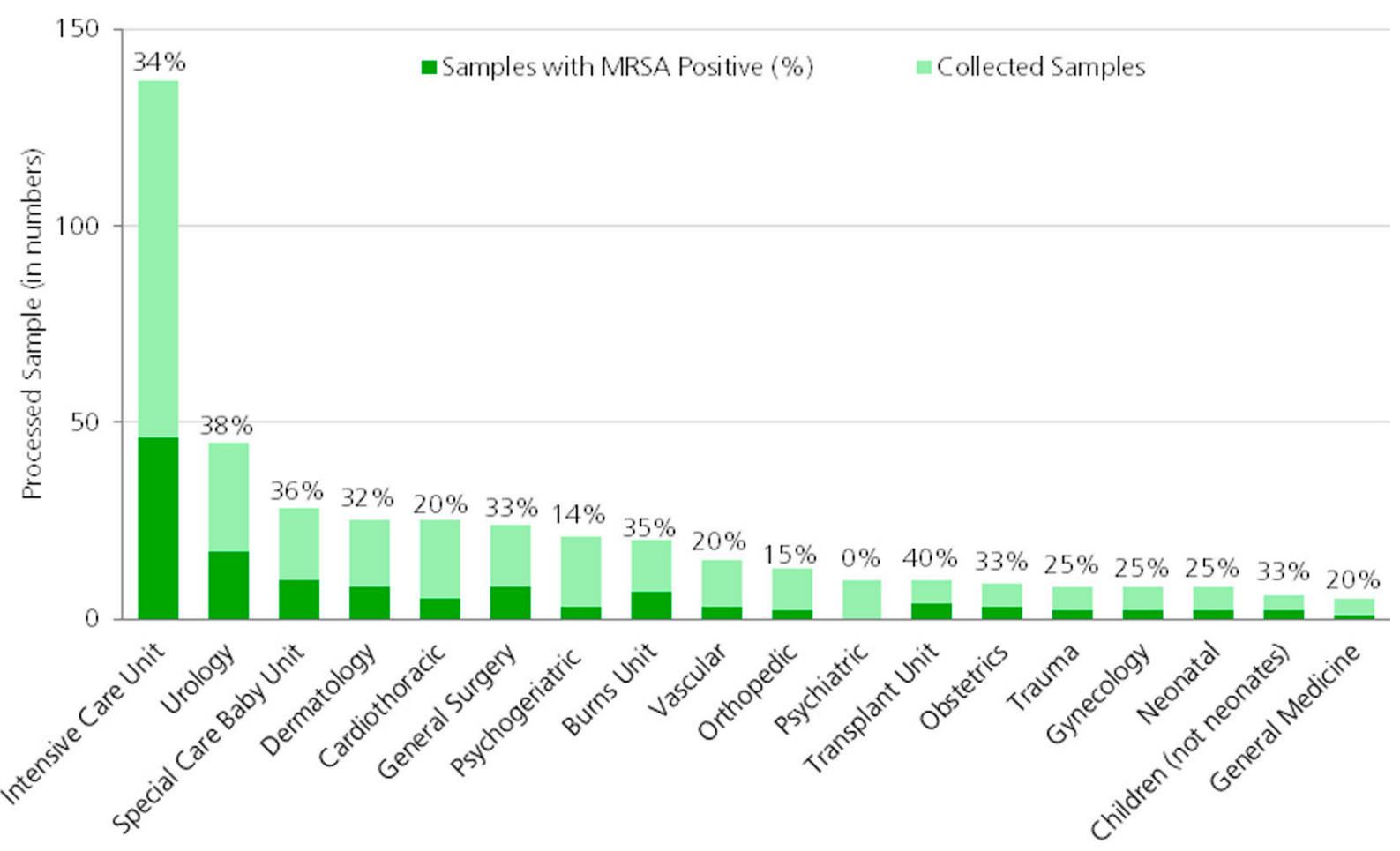

Figure 2: Processed Samples of Blood.

Blood

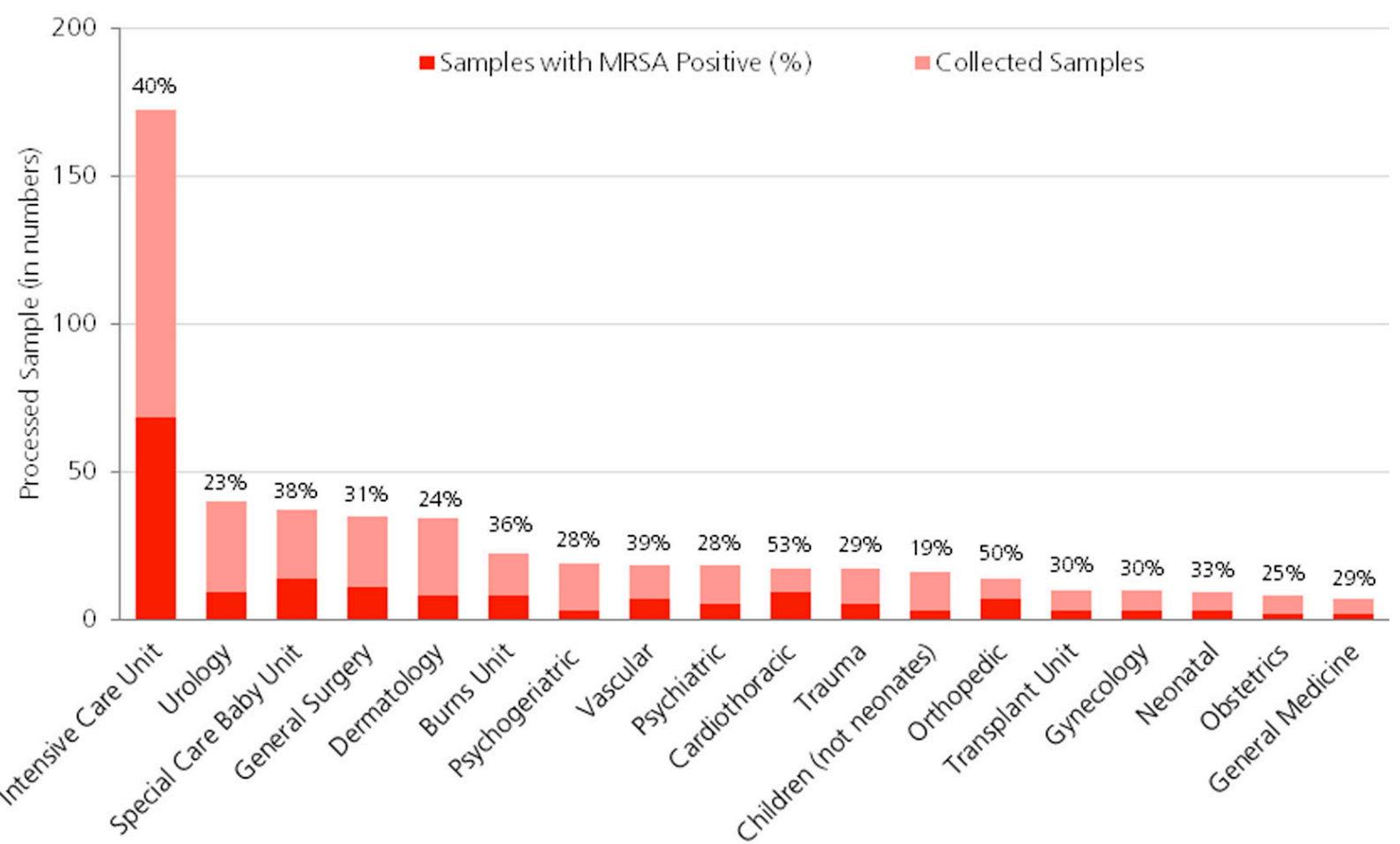


among in-door hospitalized human patients in their processed blood and urine samples.

\section{Discussion}

\section{Pre-emptive Measures (Economical and Convenient)}

Following measures are essentially taken to prevent early spread of infectious diseases. These measures must be taken by each and every individual especially persons dealing with them in healthcare systems.

Appropriate hand washing (including areas between fingers and nails) is generally accepted to be the first necessary action used for decreasing the infection risk. Alternatively, alcohol-hand-rub can be applied for decontamination. Maintain cleanliness of hands when contact with patients, replacing bed linen as well as bedding, careful handling of anything contaminated with body fluids, removing protective clothing and gloves, prior to aseptic technique, handling invasive devices and also before handling food. MRSA is both airborne and waterborne disease so maintain cleanliness of general environment including atmosphere. Also maintain an appropriate ratio of staff to patient. Keep nails clean, short as well as polish free, avoid wearing finger-ring and wristwatch, are considered among the best preventive measure $[5,17]$.

\section{Therapeutic Measures}

The use of oral antibiotics and topical Mupirocin directed towards common skin flora is the first line of treatment for mild skin infections [22]. Topical antibiotics are useful for less severe infectious cases. MRSA strains are highly resistant to various antibiotics including Cephalosporins, Macrolides and Quinolones.

The use of systemic antibiotic should be reserved for mild to moderate or severe infections that cover a large surface area. The use of an antimicrobial agent is highly recommended for the purpose of treatment. Antibiotics like Ciprofloxacin, Sulfamethoxazole, Trimethoprim, Linezolid, Rifampin or Vancomycin are right options for treatment [23]. It is noticed that most of the infections with appropriate treatment resolved within ten days. If symptoms do not resolve then the right mix of antibiotics and medicine may be recommended. It can simultaneously defend and destroy the bacterial invasion in the body and boost the self-immune system with least side effects.

\section{Alternative Remedies}

Herbal drug treatment may be adapted such as turmeric (dried rhizome of Curcuma longa belonging to family Zingiberaceae) [24], olive leaves extract, and essential oils such as tea tree oil or lavender oil, black drawing salve, bentonite clay ichthammol ointment may be applied. Specialists also suggest washing the infected area with hydrogen peroxide before applying the bentonite clay [25].

Selective range of electromagnetic waves and radio-nuclear therapy may be adopted as localized modern clinical treatment. MRSA was detected sensitive towards both solar (Ultraviolet A \& B) as well as germicidal (Ultraviolet C) ultraviolet radiation. Ultraviolet- $C$ radiation is substantially more lethal. The calculated exposure of both solar and germicidal ultraviolet radiation increases the concentration of Sodium Chloride ( $\mathrm{NaCl}$ ) medium where cells exhibit increase in sensitivity.

The most common homeopathic treatment for MRSA may include Pulsatilla and Aconitum (genera in the family of Ranunculaceae) and also belladonna (species in the family of Solanaceae) [26]. Pulsatilla is a homeopathic remedy especially recommended in women and children. Aconitum is proven to be helpful in all kinds of infection including MRSA. In homeopathic doses, belladonna remedy (extremely small doses) is also used to cure the red skin, often associated with the infections [27]. 


\section{Conclusion}

The study showed high prevalence of MRSA (37\%) among sampled in-door hospitalized human patients' fluid; who belong to Intensive Care Unit (ICU) and Special Care Baby Unit. To minimize the extent of infection, healthcare staff should make sure that they wash their hands with sterile liquid thoroughly between patient's clinical examinations. Hand washing is advised for attendants and visitors too. Healthcare associated infection should be highlighted prominently on the media at national and international level for public awareness. However, the affected patients can socialize as usual but proper decontamination of hands and use of face mask need to be incorporated. An integrated drug therapy approach should be adopted to deplete the cause and effect, and simultaneously boost the natural physiological immune system for optimum outcome.

\section{References}

1. Kim HK, Missiakas D, Schneewind O. Mouse models for infectious diseases caused by Staphylococcus aureus. Journal of Immunological Methods. 2014; 410: 88-99. doi: 10.1016/j. jim.2014.04.007.

2. Luna CM, Rodríguez-Noriega E, Bavestrello L, Gotuzzo E. Treatment of methicillin-resistant Staphylococcus aureus in Latin America. Brazilian Journal of Infectious Diseases. 2010; 14(Suppl 2):S119-S27. doi: 10.1590/S1413-86702010000800007.

3. Rashid A, Qureshi UR, Rashid A, Rashid H. Combating MRSA in Pakistan: An Integrated Drug Therapy Approach. American Journal of Life Sciences. 2015; 3(2): 71-5. doi: 10.11648/j. ajls.20150302.13.

4. Planet PJ, LaRussa SJ, Dana A, Smith $H, X u$ A, Ryan C, et al. Emergence of the Epidemic Methicillin-Resistant Staphylococcus aureus Strain USA300 Coincides with Horizontal Transfer of the Arginine Catabolic Mobile Element and speG-mediated Adaptations for Survival on Skin. mBio. 2013; 4(6): e00889-13. doi: 10.1128/mBio.00889-13.

5. Chang HR, Chang DH. MRSA and Staphylococcal Infections. Large Print ed. Raleigh, NC, United States: Lulu Press, Inc.; 2006. $81 \mathrm{p}$.

6. Rashid A, Rashid A, Rashid H, Qureshi UR. Curbing Methicillin Resistant Staphylococcus aureus: Challanges and Options in Drug Therapy. American Journal of Medicine and Medical Sciences. 2015;5(1):53-7. doi: 10.5923/j.ajmms.20150501.10.
7. Bramble M, Morris D, Tolomeo P, Lautenbach E. Potential Role of Pet Animals in Household Transmission of MethicillinResistant Staphylococcus aureus: A Narrative Review. VectorBorne and Zoonotic Diseases. 2011; 11(6): 617-20. doi: 10.1089/ vbz.2010.0025. PubMed Central PMCID: PMC3115421.

8. Stapleton PD, Taylor PW. Methicillin resistance in Staphylococcus aureus: mechanisms and modulation. Science Progress. 2007; 85(Pt 1): 57-72.

9. Simor A, Boyd D, Louie L, McGeer A, Mulvey M, Willey B. Characterization and proposed nomenclature of epidemic strains of MRSA in Canada. The Canadian Journal of Infectious Diseases. 1999; 10(5): 333-6. PubMed Central PMCID: PMC3250711.

10. Miller RR, Price JR, Batty EM, Didelot X, Wyllie D, Golubchik $T$, et al. Healthcare-associated outbreak of meticillin-resistant Staphylococcus aureus bacteraemia: role of a cryptic variant of an epidemic clone. The Journal of Hospital Infection. 2014; 86(2): 83-9. doi: 10.1016/j.jhin.2013.11.007. PubMed Central PMCID: PMC3924019.

11. Kumari HBV, Nagaraja D, Nagarathna S, Kulkarni GB, Praveen CS, Nadig S, et al. A variant epidemic methicillin resistant Staphylococcus aureus-15 cavernous sinus thrombosis and meningitis: A rare occurrence with unusual presentation. Indian Journal of Medical Microbiology. 2010; 28(3): 2557. doi: 10.4103/0255-0857.66492. PubMed Central PMCID: PMC20644319.

12. Perry JD, Rennison C, Butterworth LA, Hopley ALJ, Gould FK. Evaluation of S. aureus ID, a New Chromogenic Agar Medium for Detection of Staphylococcus aureus. Journal of Clinical Microbiology. 2003; 41(12): 5695-8. doi: 10.1128/ JCM.41.12.5695-5698.2003. PubMed Central PMCID: PMC309024

13. Flayhart D, Lema C, Borek A, Carroll KC. Comparison of the BBL CHROMagar Staph aureus Agar Medium to Conventional Media for Detection of Staphylococcus aureus in Respiratory Samples. Journal of Clinical Microbiology. 2004; 42(8): 3566-9. doi: 10.1128/JCM.42.8.3566-3569.2004. PubMed Central PMCID: PMC15297498.

14. Siegrist J. Media for detection of Staphylococcus aureus: a Spreading Bacteria. AnalytiX [Internet]. February 23, 2015; 10(Article 2): [1-4 pp.]. Available from: http://www.sigmaaldrich. com/technical-documents/articles/analytix/staphylococcusaureus.html.

15. Pournajaf A, Ardebili A, Goudarzi L, Khodabandeh M, Narimani T, Abbaszadeh H. PCR-based identification of methicillinresistant Staphylococcus aureus strains and their antibiotic resistance profiles Asian Pacific Journal of Tropical Biomedicine. 2014;4(Suppl 1): S293-S7. doi: 10.12980/APJTB.4.2014C423. PubMed Central PMCID: PMC4025288.

16. Cappuccino J, Sherman N. Microbiology: A Laboratory Manual. 10th ed. Boston, MA, United Sates: Pearson - Benjamin Cummings; 2013. $560 \mathrm{p}$ 
17. Engelkirk PG, Duben-Engelkirk J. Burton's Microbiology for the Health Sciences. 10th ed. Philadelphia, PA, United States: Wolters Kluwer Health; 2015. 498 p.

18. Mimica MJ, Berezin EN, Carvalho RLB, Mimica IM, Mimica LMJ, Sáfadi MAP, et al. Detection of methicillin resistance in Staphylococcus aureus isolated from pediatric patients: is the cefoxitin disk diffusion test accurate enough? Brazilian Journal of Infectious Diseases. 2007; 11(4): 415-7. doi: 10.1590/S141386702007000400009.

19. Ajantha GS, Kulkarni RD, Shetty J, Shubhada C, Jain P. Phenotypic detection of inducible clindamycin resistance among Staphylococcus aureus isolates by using the lower limit of recommended inter-disk distance. Indian Journal of Pathology and Microbiology. 2008; 51(3): 376-8. doi: 10.4103/03774929.42515. PubMed Central PMCID: PMC18723962.

20. Rennie RP, Koeth L, Jones RN, Fritsche TR, Knapp CC, Killian $\mathrm{SB}$, et al. Factors Influencing Broth Microdilution Antimicrobial Susceptibility Test Results for Dalbavancin, a New Glycopeptide Agent. Journal of Clinical Microbiology. 2007; 45(10): 31514. doi: 10.1128/JCM.02411-06. PubMed Central PMCID: PMC17670919.

21. Hombach M, Zbinden R, Böttger EC. Standardisation of disk diffusion results for antibiotic susceptibility testing using the sirscan automated zone reader. BMC Microbiology. 2013; 13(225): 1-8. doi: 10.1186/1471-2180-13-225.

22. Grindstaff TL, Saliba SA, Mistry DJ, MacKnight JM. CommunityAssociated Methicillin-Resistant Staphylococcus aureus. North American Journal of Sports Physical Therapy. 2007; 2(3): 13846. PubMed Central PMCID: PMC2953299.

23. Cosgrove SE, Auwaerter PG. Staphylococcus aureus: Johns Hopkins Antibiotic (ABX) Guide; 2013 [February 10, 2015]. Available from: http://www.hopkinsguides.com/hopkins/ub/ view/Johns_Hopkins_ABX_Guide/540518/all/Staphylococcus_ aureus.

24. Gupta A, Mahajan S, Sharma R. Evaluation of antimicrobial activity of Curcuma longa rhizome extract against Staphylococcus aureus. Biotechnology Reports [Internet]. 2015 Februray 26, 2015. Available from: http://www.sciencedirect.com/science/ article/pii/S2215017X15000090.

25. Kavanaugh NL, Ribbeck K. Selected Antimicrobial Essential Oils Eradicate Pseudomonas spp. and Staphylococcus aureus Biofilms. Applied and Environmental Microbiology. 2012; 78(11): 4057-61. doi: 10.1128/AEM.07499-11. PubMed PMID: PMC3346404.

26. Halcón L, Milkus K. Staphylococcus aureus and wounds: A review of tea tree oil as a promising antimicrobial. American Journal of Infection Control.32(7):402-8. doi: 10.1016/j.ajic.2003.12.008.

27. Edwards-Jones $V$, Buck $R$, Shawcross SG, Dawson MM, Dunn K. The effect of essential oils on methicillin-resistant Staphylococcus aureus using a dressing model. Burns. 30(8): 772-7. doi: 10.1016/j.burns.2004.06.006.

\section{Comment on this article:}

\section{(f) [in is $\mathbf{S}$ ?}

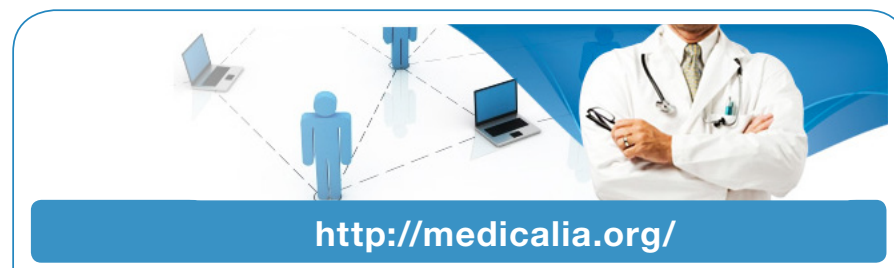

Where Doctors exchange clinical experiences, review their cases and share clinical knowledge. You can also access lots of medical publications for free. Join Now!

\section{Publish with iMedPub}

http://www.imed.pub

International Archives of Medicine is an open access journal publishing articles encompassing all aspects of medical science and clinical practice. IAM is considered a megajournal with independent sections on all areas of medicine. IAM is a really international journal with authors and board members from all around the world. The journal is widely indexed and classified Q1 in category Medicine. 